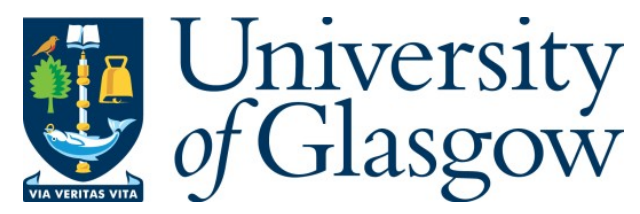

Carter, J. A. and Gordon, E. (2020) Is searching the internet making us intellectually arrogant? In: Tanesini, A. and Lynch, M. P. (eds.) Polarisation, Arrogance, and

Dogmatism: Philosophical Perspectives. Routledge, pp. 88-103. ISBN 9780367260859

(doi: $10.4324 / 9780429291395-9)$

This is the Author Accepted Manuscript.

There may be differences between this version and the published version. You are advised to consult the publisher's version if you wish to cite from it.

https://eprints.gla.ac.uk/206156/

Deposited on: 18 March 2021

Enlighten - Research publications by members of the University of Glasgow http://eprints.gla.ac.uk 
Forthcoming in Lynch, M. and Tanesini, A. (eds.) Arrogance and Polarisation, Routledge.

\title{
Is Searching the Internet Making Us Intellectually Arrogant?
}

\author{
J. Adam Carter \\ University of Glasgow \\ adam.carter@glasgow.ac.uk \\ Emma C. Gordon \\ University of Glasgow \\ emma.gordon@glasgow.ac.uk
}

\begin{abstract}
In a recent and provocative paper, Matthew Fisher, Mariel Goddu, and Frank Keil (2015) have argued, on the basis of experimental evidence, that 'searching the Internet leads people to conflate information that can be found online with knowledge "in the head"' $(2015,675)$, specifically, by inclining us to conflate mere access to information for personal knowledge $(2015,674)$. This paper has three central aims. First, we briefly detail Fisher et al's results and show how, on the basis of recent work in virtue epistemology (e.g., Tiberius and Walker 1998; Roberts and Wood 2007; Tanesini 2016), their interpretation of the data supports the thesis that searching the Internet is conducive to the vice of intellectual arrogance. Second, we argue that this arrogance interpretation of the data rests on an implicit commitment to cognitive internalism. Thirdly, we show how the data can be given a very different explanation in light of the hypothesis of extended cognition (e.g., Clark and Chalmers 1998; Clark 2008) - one which challenges the extent to which Fisher et al. are entitled to insist that subjects are actually conflating access to knowledge for personal knowledge in the first place. We conclude by suggesting how, against the background of extended cognition rather than cognitive internalism, we have some reason to think that searching the Internet might actually foster (in certain circumstances) virtuous intellectual humility.
\end{abstract}

\section{THE CONFLATION HYPOTHESIS AND THE ILLUSION OF KNOWLEDGE}

It's well-documented that our self-assessments are often inflated (e.g., Dunning 2012; Pronin 2009; Alicke et al. 1995), even when we're estimating how good we are at offering good explanations in familiar domains (e.g. Fernbach et al. 2013). Meanwhile, we are increasingly in the habit of outsourcing many of our cognitive tasks to the Internet. For example, while we might store in biomemory where to find particular information (e.g., which search terms to use, which websites or apps to consult), we rely on 
the Internet to actually store this information for us (Clark 2008; 2015; Sparrow, Liu, and Wegner 2011; Lynch 2014; 2016) ${ }^{1}$.

In combination, these tendencies might lead us to over-estimate our own levels of knowledge-viz., to think that we know more than we actually do. Though one might think that we're surely consciously aware that we're looking to an external source, e.g., the Internet, when we are, Fisher et al. (2015) suggest that the Internet's reliable and almost immediate provision of huge amounts of expert information makes it different from other external sources, and that these features might 'cause us to lose track of our reliance upon it, distorting how we view our own abilities' $(2015,675)$. More specifically, the thought is that while we might be entirely aware that we have acquired certain knowledge from the Internet, we might over-estimate 'how much of the sum total of knowledge is stored internally'.

In support of the hypothesis that online searches lead to an illusion whereby 'externally accessible information is conflated with knowledge "in the head"' $(2015,682)$ call this the conflation hypothesis-Fisher et al. draw from nine different experiments showing what they see as (various forms of) mistaken increases in self-assessed knowledge as a result of online searching ${ }^{2}$. The first two experiments show that searching for explanations on the Internet increases one's self-assessed ability to answer questions about an unrelated topic ${ }^{3}$, while a third shows that this result occurs even after time, content and features of the search process have been controlled for. Meanwhile, another three experiments show that this tendency comes not from (i) general overconfidence, or (ii) a different understanding of what counts as internal knowledge ${ }^{4}$, but rather from a genuine misattribution of the sources of knowledge.

Since one alternative interpretation of their data is that search activity merely leads us to think that we have better access to knowledge, they take pains to point out that their follow-up studies show that participants really do think they have more individual knowledge (not just better access). Fisher et al. posit that the 'illusion of knowl-

\footnotetext{
${ }^{1}$ Increased cognitive outsourcing-or cognitive scaffolding-on extra-organismic parts of the world (e.g., the Internet, smartphones, Google Glass, tablets, etc.) has been a topic of recent interest in the literature on extended cognition in the philosophy of mind and cognitive science (e.g., Clark and Chalmers 1998), and also in the literature on the intersection of extended cognition and epistemology (e.g., Carter and Palermos 2015; Carter and Kallestrup 2016; Pritchard 2010).

${ }^{2}$ See also Ward (2013) for a related study, which indicates that when people search for fact-based information on the Internet, they seem to think they came up with answers by themselves when they've actually used Google to retrieve them.

${ }^{3}$ Participants in the group using the Internet to find explanations even expected to have demonstrably increased brain activity (which they were told corresponded to higher quality explanations) when answering questions unrelated to their Internet searches.

${ }^{4}$ Fisher et al. use 'internal' knowledge and 'personal' knowledge interchangeably, to refer to information that is stored intracranially. In $\$ \$ 3-4$ we discuss some potential problems for this kind of identification, in connection with debates about cognitive internalism and externalism.
} 
edge' in these cases comes from the act of searching itself-the increase in self-assessed knowledge generalizes across popular/effective and less popular/effective search engines, and is seen even when the search engine doesn't produce relevant answers (or even any answers) to the search queries inputted ${ }^{5}$.

\section{FROM KNOWLEDGE CONFLATION TO INTELLECTUAL ARROGANCE}

In sum, then, the conflation hypothesis posited by Fisher et al. maintains that online searching generates a kind of illusion whereby 'externally accessible information is conflated with knowledge "in the head"'. In this section we want to briefly canvass how the conflation thesis appears to naturally motivate a further and potentially more philosophically vexing conclusion: that online searching indirectly facilitates (at least a kind of) intellectual arrogance. Specifically, searching may cause our intellectual self-conceptions-viz., our self-conceptions about what knowledge we're entitled to lay claim to-to be artificially inflated in a way that is conducive to vicious inferences about one's entitlements and standing in relation to others. It is, after all, a short step from thinking one knows more than one does, to acting in characteristically arrogant ways that reflect such a misconception ${ }^{6}$.

If online searching fosters intellectually vicious arrogance (even indirectly), then provided an individual's intellectual worth is at least partly a matter of her intellectual character traits (along with her knowledge base) ${ }^{7}$, it looks as though we have some (defeasible) reason to curtail or modify the mechanisms of online searching in light of Fisher et al's findings. In addition, it would be a reason that goes beyond just that internet searching engenders conflation of one knowledge source for another. This, we think, would (in light of the ubiquity of cognitive outsourcing) be a concerning result with implications not only in epistemology but in the philosophy of education ${ }^{8}$. We will be turning a critical eye to this arrogance interpretation of the data in the next section. But first, some ground clearing is necessary in order to see how such an

\footnotetext{
${ }^{5}$ Fisher et al. also speculate we might see a similar illusion of knowledge when searching for information via other sources, e.g. when an expert librarian accesses a reference Rolodex, and they mention some research suggesting we do this in highly integrated social environments, e.g., a cockpit crew conflating knowledge 'in the head' with knowledge stored in the heads of other crew members.

${ }^{6}$ In a provocative article in the New Statesman, Amanda Tait suggests that constant internet access might leave one to think one knows everything one needs towhat she terms 'omniscience bias'. http://ww. newstatesman.com/internet/2014/06/ omniscience-bias-how-internet-makes-us-think-we-already-know-everything.

${ }^{7}$ See, for example, Baehr (2011) for a notable defence of this position.

${ }^{8}$ The question of how, and to what extent, technology should be incorporated in teaching and learning in classrooms is a key contemporary theme in the philosophy (and epistemology) of education. See, for example, Elgin 1999; Carter and Kotzee 2015; Kotzee 2011; 2013.
} 
'arrogance' interpretation could most plausibly stated in connection with Fisher et al's results.

To begin, it's important to note that the matter of what constitutes intellectual arrogance is itself a question of philosophical dispute ${ }^{9}$. For starters, intellectual arrogance is plausibly not merely, or even necessarily, just a matter of over-estimation of one's own abilities or knowledge states (e.g., Tiberius and Walker 1998; Roberts and Wood 2007; Tanesini 2016) ${ }^{10}$. This means that, from the simple fact that the conflation hypothesis trivially entails an over-estimation of one's own knowledge states, it wouldn't thereby follow trivially from the conflation hypothesis that online searching makes individuals more intellectually arrogant. That said, the propensity to over-estimate one's knowledge states can play-albeit indirectly-an important role in fostering intellectual arrogance. The move from the conflation hypothesis to intellectual arrogance is thus best understood as an indirect rather than a direct one.

In order to appreciate this point, let's briefly consider three leading characterisations of intellectual arrogance: the entitlement model, the self-delusion model and the interpersonal model. Firstly, according to the entitlement model (e.g., Roberts and Wood 2007, 243), intellectual arrogance is 'a disposition to "infer" some illicit [intellectual] entitlement from a supposition of one's superiority, and to think, act, and feel on the basis of that claim'. On the entitlement model, what accounts for the intellectual arrogance of, for example, the 'college president with two doctorates who thinks himself competent to speak with correcting authority in all the fields of his faculty' (Roberts and Wood 2007, 243) is not his overestimation of his ability, per se, but more specifically his inference from his high opinion of his abilities to a claimed entitlement to behave in certain ways toward others.

According to the self-delusion model (e.g., Tanesini 2016), intellectual arrogance is 'bounded up with delusional wishful thinking'-in particular, by acquiring the frame of mind in which the " "mine-ness" of a thought' is taken by one to be a marker of its truth. For example, on this model, the intellectual arrogance of presuming (all things equal) that one's own opinion should be given special weight in comparison to others is explained by one mistakenly taking the 'mine-ness' of her thought as indicating more than it does about the truth of a belief.

Finally, on the interpersonal model (e.g., Tiberius and Walker 1998) intellectual arrogance involves a high opinion of one's intellectual worth, on the basis of which one infers a comparative intellectual superiority over others. As with the entitlement

\footnotetext{
${ }^{9}$ See, for example, Tiberius and Walker 1998, Roberts and Wood 2007 (Ch. 9) and Tanesini 2016 for some representative discussions.

${ }^{10}$ As Tanesini 2016 puts this point: 'Unless the arrogant individual is hubristic in his arrogance and claims for himself perfection, he may even have an accurate picture of his intellectual worth if he has much to be proud about. Conversely, it would seem possible to be mistaken about o e s achievements or skills without being arrogant' $(2016,12)$.
} 
model, the interpersonal model locates intellectual arrogance not in the beliefs one has about one's aptitude, simpliciter, but in the inferences that one is disposed to draw from such beliefs. The entitlement model is neutral with respect to the interpersonal character of the vice of intellectual arrogance (e.g., some infer entitlements to behave toward others in certain ways, others might not), whereas Tiberius and Walker are taking a crucial feature of intellectual arrogance to be the comparative attitudes one infers about oneself in relation to others, and how this manifests in hierarchical and non-reciprocal relationships with others $(1998,382)$.

Despite their individual differences, notice that all three accounts of intellectual arrogance involve at least some kind of high opinion of one's own intellectual status, where 'high' can be understood along the lines of 'above the mean', or 'meriting intellectual praise ${ }^{11}$. Such a high self-intellectual opinion, which is precluded by some accounts of intellectual humility (e.g., Church and Samuelson, forthcoming), is thus a crucial enabling condition of intellectual arrogance on each of the three above accounts: (i) on the entitlement and (ii) interpersonal accounts because it is from such a high opinion of one's own intellectual merit that the arrogant individual makes intellectually vicious inferences about what she's entitled to (entitlement model), and how she compares to others (interpersonal model), and (iii) on the self-delusion model, such a self-directed opinion underscores one's appraisal of the epistemic status of one's own beliefs.

Putting this all together, if Fisher et al. are right that searching the Internet causes us to systematically overestimate how much knowledge we can righty claim for ourselves, then doing so is conducive to increased estimates of one's own (personal) intellectual self-worth-exactly of the sort that is a crucial element of intellectual arrogance according to all three models canvassed. This is, prima facie, a consideration that militates against online searching, at least from a perspective where what matters is one's intellectual character.

\section{EXTENDED COGNITION AND EXTENDED KNOWLEDGE}

Two salient responses to the worry sketched in $\$ 2$ would be to either (i) contest the empirical data or (ii) to accept it and then argue that the intellectual benefits of online searching outweigh the deleterious effects doing so is likely to have on one's intellectual character in such a way as to offset any reason for curtailing online searching. We will be opting for neither strategy.

Rather, we think there is scope to accept Fisher et al.s empirical results, but to view them through the lens of a very different kind of philosophical assumption about the

\footnotetext{
${ }^{11}$ These ways of unpacking high intellectual opinion can be contrasted with 'high' opinion understood as an absolute measure.
} 
bounds of human cognising than that on the basis of which Fisher et al. are interpreting their results-namely, cognitive internalism. According to cognitive internalism (e.g., Adams and Aizawa 2001; 2008; 2010) an individual's mind is (in short) in her head. Put more carefully: the material realisers of cognitive processes (e.g., memory, inference, introspection, etc.) are exclusively intracranial processes, which play out inside the head. Thus, against a background of cognitive internalism, a cognitive process like 'memory' cannot in principle criss-cross the boundaries of the brain and world, no matter how it is we are using extra-organismic parts of the world to help us with the kind of tasks we're inclined to call 'cognitive' tasks (e.g., maths, reasoning, planning, etc. $)^{12}$.

Cognitive internalism implies that memory knowledge-viz., knowledge one has in virtue of what one remembers-is internal knowledge, knowledge one has in virtue of one's intracranial cognitive processes and states representing the world correctly. Necessarily, if this position is assumed, then the following is true. For any individual and item of information, if that information is stored outside (but not inside) the head-no matter what is true about the subject's access to it - that subject lacks memory knowledge of the information in question. If the information is easily accessible to the subject, then she at best knows how to find it. But she can't possibly know the information, despite such access, given where it is stored.

Fisher et al.s conflation hypothesis presupposes cognitive internalism. If cognitive internalism were not already taken for granted, then it should be an entirely open question whether one is conflating access to knowledge with personal knowledge, in any given case; identifying the former as the latter needn't itself be a conflation, given that a denial (but not an acceptance) of cognitive internalism is compatible with some personal knowledge being extracranially stored.

Crucially, though, the thesis that some personal knowledge can be-and indeed often times is-extracranially stored has received an array of endorsements over the past two decades. This is for broadly two reasons: the first is that Clark and Chalmers' (1998) influential challenge to cognitive internalism in their landmark 1998 paper 'The Extended Mind' has generated a range of support for the hypothesis of extended cognition (roughly: the denial of cognitive internalism ${ }^{13}$ ) in the philosophy of mind and cognitive science ${ }^{14}$. The second is that there has been a recent wave of work at the intersection of mainstream epistemology and the extended cognition literature, which has vindicated, with reference to the hypothesis of extended cognition, various forms

\footnotetext{
${ }^{12}$ When we store information in iPhones and smartwatches, or in the cloud, the information in our gadgets is not, on the internalist view, part of our 'memory', even if we use such gadgets to perform the kinds of information storage and retrieval tasks traditionally performed by biological memory.

${ }^{13}$ See Cater et al. (2014) for a taxonomy of varieties of cognitive externalism.

${ }^{14}$ See, for example, Clark 2008; 2010a; 201ob; Menary 2006; Palermos 2011; 2014b; 2014a; Barnier et al. 2008; Theiner, Allen, and Goldstone 2010; Wheeler 2005; Wilson 2004.
} 
of extended knowledge. In particular, this area of research has defended mechanisms of acquiring extended memory knowledge, as when one knows something via possession of information stored externally, provided the storage and retrieval are executed in a suitably epistemically virtuous manner ${ }^{15}$.

Both the hypothesis of extended cognition, as well as the related notion of extended knowledge, can be articulated through Clark and Chalmers' classic examplepair of Inga and Otto $(1998,8)$.

Inga: Inga has a normally functioning biological memory. When she learns new information, she stores it in her biological memory (as is typical and familiar) and it is her biological memory which she consults when she needs old information.

Otto: Otto suffers from Alzheimer's disease, and like many Alzheimer's patients, he relies on information in the environment to help structure his life. Otto carries a notebook around with him everywhere he goes. When he learns new information, he writes it down. When he needs some old information, he looks it up. For Otto, his notebook plays the role usually played by a biological memory $(1998,8)$.

Clark and Chalmers' take on the situation is that, rather than to focus on material constitution or physical location, we should instead let the following 'parity' principle guide our judgments of what counts as a part of an individual's cognitive process:

Parity Principle: If, as we confront some task, a part of the world functions as a process which, were it to go on in the head, we would have no hesitation in accepting as part of the cognitive process, then that part of the world is part of the cognitive process ${ }^{16}$.

Given that Otto's notebook is playing the same functional role vis-à-vis the task of information storage and retrieval as is Inga's biological brain is playing-we should, with reference to the parity principle, include Otto's notebook as part of his memory provided we include Inga's biological memory as part of her memory (which, of course, we do). And this means recognising that the material realisers of cognitive processes needn't be exclusively intracranial, but rather, as Clark puts it, that-at least in certain circumstances-'the actual local operations that realize certain forms

\footnotetext{
${ }^{15}$ The pairing of extended cognition and virtue epistemology has been perhaps the most popular epistemological strategy for defending extended knowledge. See, for example, Carter 2018; Carter and Palermos 2014; Pritchard 2010; Palermos 2014a; Kelp 2013; Palermos and Pritchard 2013.

${ }^{16}$ For some alternative motivations for extended cognition which do not rely on the parity principle, see for example Donald 1991; Menary 2006; Palermos 2014a; 2014b; Sutton; 2010.
} 
of human cognizing include inextricable tangles of feedback, feed-forward and feedaround loops: loops that promiscuously criss-cross the boundaries of brain, body and world' (Clark 2007, \$2).

One common form of objection to cognitive externalism (or, as Clark and Chalmers put it, 'active externalism ${ }^{17}$ ') is that it's not clear enough (at least, with just the parity principle in play) what conditions must be in place for Otto's notebook to count as playing the relevantly same kind of functional role as Inga's memory. And without suitable demarcation conditions, the parity principle risks potentially 'ruling in' too much. In response to this kind of 'cognitive bloat' objection ${ }^{18}$, Clark articulates several 'glue and trust' conditions which should be satisfied by any artefact that is to be included as part of an extended memory process:

\section{Clark's "Trust and Glue" Integration Conditions}

(1) 'That the resource be reliably available and typically invoked."'

(2) 'That any information thus retrieved be more-or-less automatically endorsed. It should not usually be subject to critical scrutiny. [...] It should be deemed about as trustworthy as something retrieved clearly from biological memory'

(3) 'That information contained in the resource should be easily accessi-

ble as and when required.'

With reference to these conditions, Otto's notebook is 'ruled in' as part of his memory, whereas, say, a telephone book consulted on occasion would be ruled-out.

Of course, it's one thing to say that Otto has an extended memory process, but quite another thing to say that Otto's information, stored in his notebook, qualifies as knowledge that we can credit to him. Put another way: it doesn't follow simply from an extended cognition gloss of cases like Otto's that Otto can be credited with knowledge of the information stored in the notebook, even if such information is, on extended cognition, in bona fide extended memory storage. Any such explanation will require an epistemological account of the status of Otto's extended memory information, and not merely a metaphysical explanation of Otto's memory process.

Here, the most influential epistemological strategy on offer is due to Duncan Pritchard (2010), who takes as a starting point—broadly in the spirit of virtue epistemologythat knowledge must be a kind of success that is creditable to the cognitive abilities of the agent ${ }^{19}$. One might initially think that this is precisely what is not going on

\footnotetext{
${ }^{17}$ Active, here, is meant to contrast with the kind of 'passive' externalism that characterises content externalism, the view that meaning and mental content are externally individuated (e.g., Putnam 1975; Burge 1986).

${ }^{18}$ See, for example, Adams and Aizawa 2011; Rupert 2004; Allen-Hermanson 2013.

${ }^{19}$ For some seminal defences of this position, see Greco 2010; Sosa 2009; 2015; Zagzebski 1996.
} 
in cases when information is stored extracranially, because it appears that one's own ability is disconnected from the matter of whether she attains success, i.e., true belief. However, such an initial reaction may rely on a presumption, rejected by proponents of extended cognition, that the only sort of processes that could underwrite abilities are intracranial processes.

At this juncture, Pritchard's key insight, when thinking about cases like Otto's, is that satisfying the kinds of integration conditions that needed for extended cognition (e.g., Clark's Glue and Trust conditions) might well also suffice to satisfy at least one plausible version of virtue reliabilism (e.g., (Greco 2003; E. Sosa 2009) according to which one knows a proposition only if one's true is the 'product of a reliable beliefforming process which is appropriately integrated within $S$ 's cognitive character, such that her cognitive success is to a significant degree creditable to her cognitive agency' $(2010,137-7)^{20}$. As Pritchard sees it, Otto's extended cognitive process of consulting the notebook plausibly meets such a virtue reliabilist condition. As he writes:

Otto's acquisition of the notebook, and his systematic use of it, represents a great deal of epistemic virtue on his part. A lesser cognitive agent-i.e., one who was less interested in gaining and retaining true beliefs about his environment-would have acquiesced in the loss of his (non-extended) memory and so accepted the epistemic consequences. Moreover, notice that the way in which Otto employs the notebook also reflects his epistemic virtue. An agent less concerned with epistemic goods would not, for example, go to the lengths that Otto goes to in order to ensure that this information resource is readily available to him but really would just use this notebook as a mere incidental aid to his cognition $(2010,145)$.

And, indeed, as Katalin Farkas (2016) has argued ${ }^{21}$ :

Otto has knowledge because his cognitive success is due to his cognitive ability, since he relies on a reliable entry-forming process that is integrated with his cognitive character[...]

The reader at this stage might see where this is all headed. It's an entirely incidental feature of Otto's notebook that it is made of paper. In fact, most notebooks and external memory storage artefacts nowadays are online, accessible through apps on our gadgets, with information stored in the cloud, and with which we interact in ways

\footnotetext{
${ }^{20}$ See here also Palermos (2014a).

${ }^{21}$ Farkas's reading of the case, however, maintains that Otto has extended knowledge without extended belief, and thus rejects the orthodox view that knowledge entails belief (see, along with Farkas 2016, also Farkas 2015).
} 
that mimic in relevant respects the fashion that Otto is relying on his notebook. ${ }^{22}$ In short, the kinds of arguments that we've seen support classifying Otto as knowing extracranial information in his notebook are going to apply mutatis mutandis for our information stored in gadgets and on the web, provided that we interact with our gadgets in an analogously responsible and epistemically virtuous manner ${ }^{23}$.

\section{AN ALTERNATIVE HYPOTHESIS}

If the rationale canvassed in $\$_{3}$ is on the right track, then the question of whether an individual storing information not in her head, but in the cloud, knows that information isn't settled simply with reference to the fact that the information is not in her head. What's relevant is how the individual is interacting with the relevant information-storing gadget; for example, is the gadget appropriately cognitively integrated by the lights of the conditions outlined in $\$_{3}$ ?

In cases where the answer is 'yes', there is at least a precedent for thinking that the individual's own personal knowledge can be stored online. This precedent (drawing from both extended cognition and virtue epistemology) is also one on the basis of which we are in a position to reject as a false dichotomy Fisher et al's distinction between personal knowledge and access to knowledge. On Farkas's (2016) view, for instance, 'Otto knows where the Museum of Modern Art is, because he has appropriate access to the information that the Museum of Modern Art is on 53d street' where 'appropriate' access is the kind of access one has only when the external information storage and retrieval process that is integrated with his cognitive character, as per Pritchard (2010; see $\$ 3$ ).

Interestingly, Fisher et al. are clearly aware of the hypothesis of extended cognition, though they do not raise the possibility that at least some participants might not be conflating access to information for personal knowledge. They note, in the article's closing paragraph, that:

There are clearly benefits to the freely accessible information on the Internet; however, there may be costs inherent to the strategy of accessing that information. The boundary between personal and interpersonal knowledge is becoming increasingly blurred (Clark \& Chalmers, 1998). As technology makes information ever more easily available and accessible through searching, the ability to assess one's internal "unplugged"

\footnotetext{
${ }^{22}$ See, for example, Heersmink 2015; 2016; Smart, Heersmink, and Clowes 2016.

${ }^{23}$ The paradigmatic kind of case here will be one where Otto simply stores his information on various apps, which he then searches as a matter of second nature, to retrieve the relevant information.
} 
knowledge will only become more difficult. Erroneously situating external knowledge within their own heads, people may unwittingly exaggerate how much intellectual work they can do in situations where they are truly on their own.

A proponent of extended knowledge will agree with Fisher et al, that the boundary between personal and interpersonal knowledge ${ }^{24}$ is becoming increasingly blurred, but go further and maintain that some externally stored information plausibly falls in the category of personal rather than interpersonal knowledge.

Of course, one might attempt to stipulate by fiat that personal knowledge must refer to knowledge attained through processes internal to the biological agent. However, this is in effect to beg the question against the proponent of extended knowledge. Andy Clark, for example, in his recent paper 'What 'Extended Me' Knows' (2015) emphasises how the subject of externally stored knowledge is the person who has integrated the relevant technology through the right kind of epistemic hygiene; there is no basis within this kind of position to regard this knowledge as not personal knowledge. Indeed, what explains the information as knowledge is (at least, within the kind of virtue-epistemic framework Pritchard (e.g., 2010) is appealing to, and which Farkas and Clark are sympathetic to) that the success in question is appropriately creditable to the agent ${ }^{25}$. In a similar vein, Richard Heersmink (2016) has argued that the personal character of extended memory knowledge is crucial to personal identity ${ }^{26}$. He sums up the key contours of this position thusly:

On an extended and distributed approach to cognition, external information is under certain conditions constitutive of memory. On a narrative approach to personal identity, autobiographical memory is constitutive of our diachronic self [...] [E]xternal information can be constitutive of one's autobiographical memory and thus also of one's diachronic self $(2016,1)$.

Putting this all together, it looks as though there may be less conflation taking place in the studies reported by Fisher et al. than they are assuming. This of course would depend on factors not reported by the studies, including the participants' causal histories of interaction with the devices in question, and we can expect that there will

\footnotetext{
${ }^{24}$ Note that we are not using 'interpersonal knowledge' to refer to distributed cognition, as when cognition is distributed amongst multiple individuals. Rather, we are borrowing Fisher et al's usage, which is in line with knowledge via a testimonial exchange, viz., through the intellectual labour of another.

${ }^{25}$ For a related expression of this point, see Carter and Pritchard 2019; Carter and Palermos 2014.

${ }^{26}$ For a related kind of argument, articulated in terms of extended emotion, see Carter, Gordon and Palermos 2016.
} 
be room for plenty of variability here. Nonetheless, against a background commitment to the kind of thinking canvassed in $\S_{3}$, and which rejects cognitive internalism, there is room to surmise that at least some (and perhaps a significant amount of) information Fisher et al. are classifying as interpersonal would fall within the category of personal knowledge. More generally, this means that their results, viewed through a different lens, looks much less amenable to the kind of arrogance interpretation of the results that looked very plausible against a background commitment to cognitive internalism.

On the extended knowledge interpretation of the results, it is an open question in each case whether the individual in question is conflating access to knowledge for personal knowledge, and thus an open question (which requires further investigation) whether participants are claiming for themselves knowledge they're not entitled to claim. And furthermore, it's considerably less clear how, on either of the models of intellectual arrogance which take one's relation to others as essential to intellectual arrogance (i.e., the entitlement and interpersonal models), arrogance is cultivated by claiming extended knowledge. This is because, in short, it is typically going to be common knowledge to interlocutors with online access that their interlocutors have access to much of the same information as they do. Relational attitudes of intellectual superiority of the sort that the entitlement and interpersonal models take to be endemic to intellectual arrogance thus seem to require a kind of intellectual differentiation that extended knowers, in virtue of mutually recognised common access, will be less inclined to claim.

\section{KNOWLEDGE ACCESS AND INTELLECTUAL HUMILITY}

We have to this point canvassed an alternative way of interpreting Fisher et al's results, one that takes for granted a different background way of thinking about the metaphysics of mind, and what kinds of information could qualify as personal knowledge, as opposed to mere access to knowledge. This alternative interpretation, by under-

mining the extent to which Fisher et al. take the conflation hypothesis to have been confirmed, offers a way to accept that individuals are inclined to claim as their own personal knowledge information stored online without trending toward intellectual arrogance.

We want to conclude by advancing this alternative interpretation further in two directions. Firstly, we want to reply to the following anticipated objection: that the extended knowledge interpretation of the data fails to preserve any meaningful distinction between knowledge and access to knowledge. This is, to be clear, an objection that would count not only against the kind of explanation of the results canvased in $\$ \$ 3-4$ but also more generally against the possibility of extracranially stored personal 
knowledge.

We think that this kind of objection cuts both ways. As Farkas $(2016,15)$ notes, there are some kinds of cases where we say that one knows how to find out something, but would have no temptation whatsoever to attribute knowledge to the person, unlike in cases like that of Otto, where there is such a temptation. For example, you know how to find out what your neighbour is wearing today: go knock on your neighbour's door and ask. Likewise, you know how to find out what it's like to be in Africa: go to Africa. As Farkas points out, if we simply treat cases like Otto's as cases where one merely knows how to find out the relevant information, we are in effect lumping such cases in a category that fails to distinguish Otto's epistemic position as relevantly stronger $v i s$ - $a$-vis the stored information than it would be in the other kinds of cases where one knows how to find something out but where there is no temptation whatsoever to attribute knowledge. What this suggests then is that the matter of preserving a meaningful distinction between knowing and knowing how to find out doesn't clearly speak in favour of cognitive internalism over cognitive externalism.

We want to close now by connecting the extended knowledge interpretation of the data we've outlined with the related notions of intellectual arrogance and intellectual humility. Weve already suggested that, while it's a straightforward path from searching the internet to intellectual arrogance, if cognitive internalism is assumed, this is less clearly the case if we interpret the data without this assumption in hand. We want to close by suggesting how, on our alternative way of thinking about the results sketched in $\$ \$ 3-4$, ubiquitous access to the internet could in fact have an opposite kind of effect, in that it could help to actively foster intellectual humility.

According to one prominent contemporary account of epistemic humility, defended by Whitcomb et al. (2015), virtuous intellectual humility is, at its core, a matter of owning our own intellectual limitations-something that can be manifested behaviourally by (among other ways) a willingness to appropriately defer and, as Baehr (2015) argues, to avail oneself willingly to fact-checking.

At this point, an interesting result materialises: some of the same kinds of features of internet access which lead to an arrogance worry, against the background cognitive internalism assumption, can potentially foster intellectual humility against the kind of background outlined in $\$ \$ 3-4$. Consider, for example, Ward's (2013) suggestion that that internet users are inclined to treat the internet as an 'all-knowing expert'; or Ian Leslie's suggestion that Google never responds by saying, 'I don't know-what do you think?', but instead always has an answer. Such observations, paired with a cognitive internalist reading of Fisher et al's data, are arrogance-promoting, in that they are considerations that would facilitate the conflation of knowledge access with personal knowledge. But, notice that these very same features can play an entirely different kind of role against the kind of 'active' cognitive externalist background sketched in $\$ \$ 3^{-}$ 
4. A propensity to treat the internet ${ }^{27}$, as an 'all-knowing expert' and the fact that it reliably provides informative responses are precisely the kinds of features which make extended knowers ready fact-checkers. Online access, appreciated in this way, offers a dual role of facilitating extended knowledge while at the same time making it easier for an individual's false claims to be verified by the very same mechanism-type on which the original knowledge was claimed.

We do not intend to submit that online access will outright cause intellectual humility. Instead, we think it is important to register how aspects of online searching that would tend to promote intellectual arrogance if cognitive internalism is assumed could actually militate in the opposite direction within the framework of extended epistemology, by facilitating the ways we can own our intellectual limitations.

\section{CONCLUSION}

Constant internet access is undeniably changing the way we know, both by increasing access to knowledge and by changing the way we store and retrieve information. What's of philosophical interest is what kinds of conclusions can be drawn from these indisputable descriptive facts about epistemic practice. Fisher et. al have defended the provocative conclusion that internet access leads people to conflate information that can be found online with personal knowledge. We've shown that this conclusion has an important further ramification, beyond what Fisher et al. have themselves suggested, which is that searching the internet plausibly inclines individual to intellectual arrogance, at least by the lights of three prominent contemporary views of intellectual arrogance.

We've shown further that this interpretation depends on an admittedly reading of Fisher et al's results that takes for granted cognitive internalism, the view that cognitive processes are exclusively intracranially realised. We've argued, with reference to recent work at the intersection of the philosophy of mind and cognitive science and epistemology, that there is potentially a very different kind of 'active externalist' lens through which to interpret Fisher et al's results, and it's one on which there is plausibly much less conflation of access to knowledge with personal knowledge than the authors have supposed. We conclude by developing this alternative interpretation further and we suggest how, against this very different philosophical background, pervasive online access might be conducive to the cultivation and exercise of virtuous intellectual humility. ${ }^{28}$

\footnotetext{
${ }^{27}$ Or, more accurately: the extended system that includes a person who is competent online with the technological resource itself.

${ }^{28}$ Thanks to Alessandra Tanesini for comments on a previous version of this paper.
} 


\section{REFERENCES}

Adams, Fred, and Ken Aizawa. 2001. 'The Bounds of Cognition'. Philosophical Psychology 14 (1): 43-64.

- - 2008. The Bounds of Cognition. John Wiley \& Sons.

- - 2010. 'The Value of Cognitivism in Thinking about Extended Cognition' Phenomenology and the Cognitive Sciences 9 (4): 579-603.

Adams, Frederick, and Kenneth Aizawa. 2011. The Bounds of Cognition. Blackwell.

Alicke, Mark D., Mary L. Klotz, David L. Breitenbecher, Tricia J. Yurak, and Debbie S. Vredenburg. 1995. 'Personal Contact, Individuation, and the Better-than-Average Effect.' Journal of Personality and Social Psychology 68 (5): 804.

Allen-Hermanson, Sean. 2013. 'Superdupersizing the Mind: Extended Cognition and the Persistence of Cognitive Bloat'. Philosophical Studies, 1-16.

Baehr, Jason. 2011. The Inquiring Mind. Oxford: Oxford University Press.

Barnier, Amanda J., John Sutton, Celia B. Harris, and Robert A. Wilson. 2008. 'A Conceptual and Empirical Framework for the Social Distribution of Cognition: The Case of Memory'. Cognitive Systems Research 9 (1): 33-51.

Burge, Tyler. 1986. 'Individualism and Psychology'. Philosophical Review 95 (January): $3-45$.

Carter, J. Adam. 2018. 'Virtue Epistemology and Extenced Cognition'. Routledge Handbook for Virtue Epistemology (ed.) H. Battaly, London: Routledge, pp. 420432.

Carter, J. Adam, Emma C. Gordon and S. Orestis Palermos. 2016. 'Extended Emotion'. Philosophical Psychology 29 (2): 197-218.

Carter, J. Adam and Ben Kotzee. 2015. 'Epistemology of Education'. Oxford Bibliographies Online. doi:10.1093/0bo/9780195396577.016.0292

Carter, J. Adam and Jesper Kallestrup. 2016. 'Extended Cognition and Propositional Memory' Philosophy and Phenomenological Research 92(3): 691-714.

Carter, J. Adam and Duncan Pritchard. 2019. 'Extenced Entitlement'. In New Essays on Entitlement, (eds.) P. Graham and N. Pedersen, Oxford: OUP.

Carter, J. Adam, Jesper Kallesztrup, S.O. Palermos and D. Pritchard. 2014. 'Varieties of Externalism’. Philosophical Issues (supplement to Noûs) 24 (1): 63-109. 
Carter, J. Adam and S. Orestis Palermos. 2014. 'Active Externalism and Epistemic Internalism, Erkenntnis 80: 753-772.

Church, Ian M., and Peter L. Samuelson. forthcoming. Intellectual Humility: An Introduction to the Philosophy and Science. Bloomsbury Academic.

Clark, Andy. 2008. Supersizing the Mind: Embodiment, Action, and Cognitive Extension. Oxford University Press.

- - 2 2010a. 'Coupling, Constitution and the Cognitive Kind'. In The Extended Mind, edited by Richard Menary, 81-99. Cambridge, M.A: MIT Press.

- - . 2010b. 'Memento's Revenge: The Extended Mind Extended'. In The Extended Mind, edited by Richard Menary, 43-66. MIT Press.

- - . 2015. 'What "Extended Me" Knows'. Synthese, April, 1-19. doi:10.1007/s11229015-0719-Z.

Clark, Andy, and David J. Chalmers. 1998. 'The Extended Mind'. Analysis 58 (1): 7-19.

Donald, Merlin. 1991. Origins of the Modern Mind: Three Stages in the Evolution of our Cognitive System. Cambridge, MA: Harvard University Press.

Dunning, David. 2012. Self-Insight: Roadblocks and Detours on the Path to Knowing Thyself. Psychology Press.

Elgin, Catherine Z. 1999. 'Education and the Advancement of Understanding'. The Proceedings of the Twentieth World Congress of Philosophy 3: 131-140.

Farkas, Katalin. 2015. 'Belief May Not Be a Necessary Condition for Knowledge'. Erkenntnis 80 (1): 185-200.

- - . 2016. 'Know-Wh Does Not Reduce to Know That'. American Philosophical Quarterly 53 (2): 109-122.

Fernbach, Philip M., Todd Rogers, Craig R. Fox, and Steven A. Sloman. 2013. 'Political Extremism Is Supported by an Illusion of Understanding'. Psychological Science, 956797612464058 .

Fisher, Matthew, Mariel K. Goddu, and Frank C. Keil. 2015. 'Searching for Explanations: How the Internet Inflates Estimates of Internal Knowledge. Journal of Experimental Psychology: General 144 (3): 674-687.

Greco, John. 2003. 'Knowledge as Credit for True Belief'. In Intellectual Virtue: Per- 
spectives from Ethics and Epistemology, edited by Michael DePaul and Linda Zagzebski. Oxford: Oxford University Press.

-—-. 2010. Achieving Knowledge. Cambridge: Cambridge University Press.

Heersmink, Richard. 2015. 'Dimensions of Integration in Embedded and Extended Cognitive Systems'. Phenomenology and the Cognitive Sciences 14 (3): 577-598.

- - . 2016. 'Distributed Selves: Personal Identity and Extended Memory Systems'. Synthese, 1-17.

Kelp, Christoph. 2013. 'Extended Cognition and Robust Virtue Epistemology'. Erkenntnis 78 (2): $245-252$.

Kotzee, Ben. 2011. 'Education and “Thick” Epistemology'. Educational Theory 61 (5): 549-564.

- - 2013. Education and the Growth of Knowledge: Perspectives From Social and Virtue Epistemology. Wiley-Blackwell.

Lynch, Michael P. 2014. 'Neuromedia, Extended Knowledge and Understanding'. Philosophical Issues 24 (1): 299-313.

- - . 2016. The Internet of Us: Knowing More and Understanding Less in the Age of Big Data. 1 edition. New York: Liveright.

Menary, Richard. 2006. 'Attacking the Bounds of Cognition'. Philosophical Psychology 19 (3): 329-344.

Palermos, Orestis. 2011. 'Belief-Forming Processes, Extended'. Review of Philosophy and Psychology 2 (4): 741-765.

-_- 2014a. 'Knowledge and Cognitive Integration'. Synthese 191 (8): 1931-1951.

- - . 2014b. 'Loops, Constitution, and Cognitive Extension'. Cognitive Systems Research 27: 25-41.

Palermos, Spyrion Orestis, and Duncan Pritchard. 2013. 'Extended Knowledge and Social Epistemology'. Social Epistemology Review and Reply Collective, no. 8: 105120.

Pritchard, Duncan. 2010. 'Cognitive Ability and the Extended Cognition Thesis'. Synthese 175 (1): 133-151.

- - . 2014. 'Virtue Epistemology, Extended Cognition, and the Epistemology of Education'. Universitas: Monthly Review of Philosophy and Culture 478: 47-66. 
Pronin, Emily. 2009. 'The Introspection Illusion'. Advances in Experimental Social Psychology 41: 1-67.

Putnam, Hilary. 1975. 'The Meaning of "Meaning"'. Minnesota Studies in the Philosophy of Science 7: 131-193.

Roberts, Robert C., and W. Jay Wood. 2007. Intellectual Virtues: An Essay in Regulative Epistemology. Oxford University Press.

Rupert, Robert D. 2004. 'Challenges to the Hypothesis of Extended Cognition'. Journal of Philosophy 101 (8): 389-428.

Smart, Paul, Heersmink, Richard \& Clowes, Robert. 2017. 'The Cognitive Ecology of the Internet', In S. Cowley \& F. Vallée-Tourangeau (eds.), Cognition Beyond the Brain: Computation, Interactivity and Human Artifice ( $2^{\text {nd }}$ ed.). Dordrecht: Springer.Sosa, E. 2009. A Virtue Epistemology: Apt Belief and Reflective Knowledge (Vol. 1). Oxford: Oxford University Press.

Sosa, Ernest. 2009. A Virtue Epistemology: Apt Belief and Reflective Knowledge, Volume I. OUP Oxford.

- - . 2015. Judgment and Agency. Oxford: Oxford University Press.

Sparrow, Betsy, Jenny Liu, and Daniel M. Wegner. 2011. 'Google Effects on Memory: Cognitive Consequences of Having Information at Our Fingertips'. Science 333 (6043): $776-778$.

Sutton, John. 2010. 'Exograms and Interdisciplinarity: History, the Extended Mind, and the Civilizing Process', In R. Menary (Ed.), The extended mind (pp. 189-225). Cambridge, MA: MIT Press.

Tanesini, Alessandra. 2016. 'I- "Calm Down, Dear": Intellectual Arrogance, Silencing and Ignorance'. Aristotelian Society Supplementary Volume 90 (1): 71-92. doi:10.1093/arisup/akwo11.

Theiner, Georg, Colin Allen, and Robert L Goldstone. 2010. 'Recognizing Group Cognition'. Cognitive Systems Research 11 (4): 378-395.

Tiberius, Valerie, and John D. Walker. 1998. 'Arrogance'. American Philosophical Quarterly 35 (4): 379-390.

Ward, Adrian F. 2013. 'Supernormal: How the Internet Is Changing Our Memories and Our Minds'. Psychological Inquiry 24 (4): 341-348.

Wheeler, Michael. 2005. Reconstructing the Cognitive World: The next Step. MIT 
Press.

Whitcomb, Dennis, Heather Battaly, Jason Baehr, and Daniel HowardSnyder. 2015. 'Intellectual Humility: Owning Our Limitations'. Philosophy and Phenomenological Research 91 (1).

Wilson, Robert A. 2004. Boundaries of the Mind: The Individual in the Fragile SciencesCognition. Cambridge University Press.

Zagzebski, Linda Trinkaus. 1996. Virtues of the Mind: An Inquiry into the Nature of Virtue and the Ethical Foundations of Knowledge. Cambridge University Press. 